\title{
Development of Heat Exchanger with New Mechanism of Scraping Temperature Boundary Layer
}

\author{
Hiroshi NOGAMI, ${ }^{1)}$ Kiyoo AONUMA ${ }^{21}$ and Youichi CHIBA ${ }^{3)}$ \\ 1) Ichinoseki National College of Technology, Takanashi, Hagisho, Ichinoseki 021-8511 Japan. \\ 2) Formerly Ichinoseki National College of Technology. Now at Sumitomo Chemical Co. Ltd. \\ 3) DFR Co. and Professor Emeritus, Ichinoseki National College of Technology.
}

(Received on January 28, 2010; accepted on May 12, 2010)

\begin{abstract}
In recent years various approaches to reduce carbon dioxide emission from iron- and steelmaking industry have been made, and recovery of the waste heat is one of these approaches. Heat exchanger is one of key facilities to recover the waste heat released as sensible heat of fluids. In this study a new concept to raise efficiency of heat exchanger has been proposed. The temperature boundary layer is scraped from moving heat transfer surface by rigid blades to remove the heat transfer resistance of the boundary layer. Some prototypes of the heat exchangers of double-tube type with this concept were made. The inner tube of the heat exchanger rotates and the blades are set on both sides of the inner tube. The performance of the heat exchanger was examined in various combinations of working fluids. The results showed that the overall heat transfer coefficients, which is a key parameter to expresses heat exchanger performance, increased with increase in revolution of the inner tube regardless of working fluids. Thus the effectiveness of this new concept was confirmed. The effect of the boundary layer scraping is remarkable in the liquid-liquid or liquid-steam systems, and the heat transfer coefficient increased by about ten times in some cases. For the combination including gas, although this concept is useful, there still is a room to optimize the design of the heat exchangers to improve the performance. It is expected that practical use of this heat exchanger is great help to recover the waste heat from the industries.
\end{abstract}

KEY WORDS: heat exchanger; heat transfer coefficient; boundary layer; scraping; waste heat.

\section{Introduction}

In recent years various approaches to reduce carbon dioxide emission from iron- and steelmaking industry have been made. Recovery of the waste heat is one of these approaches, and its concept is the effective use of unused energy in the industry. ${ }^{1-5)}$ The industry releases waste heat as various forms such as heat loss from furnaces, sensible heat of exhaust gases, radiation from high temperature materials, and so on. For each form of waste heat, suitable recovering methods were proposed. For example, thermoelectric conversion for wall heat loss, ${ }^{6-9)}$ pre-heating of materials and steam generation for fluid sensible heat and radiation, etc. One of the attracting technologies is latent heat storage $^{10-14)}$ that once stores thermal energy as latent heat of melting and then supplies it to the distant place with time-shift and flattened temperature level. Regarding the temperature level of the waste heat, high and middle temperature waste heats is able to be recovered fairly easily because the driving force in heat recovering process can be set high. Contrarily, temperature difference between the waste heat and heat recovering media as the heat transfer driving force is small for low temperature waste heat. This lowers the efficiency of the heat recovery, and is one of the barriers for utilization of low temperature waste heat. In many cases of the recovery of the fluid sensible heat, process of heat exchange is included in the recovery system and it could be a bottle neck of the low temperature heat recovery. Thus the use of highly efficient heat exchanger helps further extension of the low temperature heat recovery. In this study a heat exchanger having new concept to raise efficiency of heat exchange has been developed, and its performance is elucidated through experiments. Furthermore a method to improve the efficiency of this heat exchanger is investigated.

\section{Theory and Concept}

Facilities that transfer the thermal energy from high-temperature material to low-temperature material are usually called heat exchanger. Indirect heat exchanger in which the high-temperature and low-temperature materials are separated by partition wall and they exchange heat through this wall is one of the most popular styles of the heat exchangers. A temperature distribution around the partition wall in a heat exchanger is schematically shown in Fig. 1. In the arrangement in this figure, heat transfers from the high temperature fluid of which temperature is $T_{\mathrm{H}}$ to low temperature fluid $\left(T_{\mathrm{L}}\right)$ through the partition wall. The fluid region adjacent to the partition wall in which steep temperature gradient is formed is called temperature boundary layer or film, and it forms on both side of the partition wall. The 


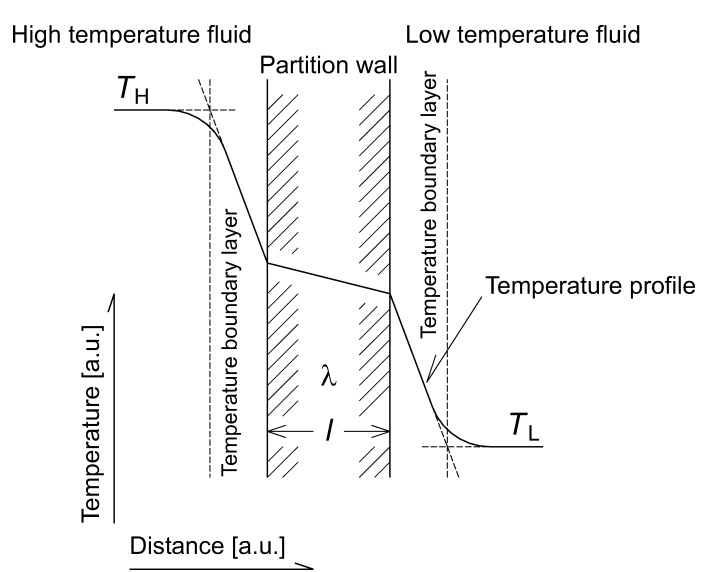

Fig. 1. Temperature profile for heat transfer between two fluid through partition wall.

temperature boundary layer works as a resistance to the heat transfer between two fluids, as the heat conduction in the partition wall does so. The heat transfer rate in the indirect heat exchanger is expressed by the following equation.

$$
Q=A h_{\text {ov }} \Delta T \text {.. }
$$

where $A, h_{\mathrm{ov}}$ and $\Delta T$ are heat transfer area, overall heat transfer coefficient and average temperature difference between high temperature and low temperature fluids $\left(\Delta T=T_{\mathrm{H}}-T_{\mathrm{L}}\right)$ in the heat exchanger. The overall heat transfer coefficient $h_{\mathrm{ov}}$ is one of the most important parameters representing the performance of the heat exchanger. Enlargement of the heat transfer area and increase in the overall heat transfer coefficient improve the heat transfer rate. For former issue, various methods are applied, for example, use of numerous fine tube, addition of fins, and so on. For flat plate the overall heat transfer coefficient $h_{\mathrm{ov}}$ is defined as

$$
\frac{1}{h_{\mathrm{ov}}}=\frac{1}{h_{\mathrm{H}}}+\frac{1}{\lambda / l}+\frac{1}{h_{\mathrm{L}}}
$$

where $h_{\mathrm{H}}, h_{\mathrm{L}}$ are the heat transfer coefficients of temperature boundary layers in high- and low-temperature fluids, $\lambda$ and $l$ are thermal conductivity and thickness of the partition wall, respectively. This equation shows the importance of the heat transmission through the temperature boundary layer because it governs the heat transfer rate in the heat exchanger. The heat transfer coefficient of the boundary layer is usually expressed as a function of positive correlation to the Reynolds number $(\operatorname{Re}=d u \rho / \mu) .{ }^{15,16)}$ To increase the heat transfer coefficient, the actions to increase the Reynolds number, for example increase in fluid velocity $(u)$, are employed. These approaches are usually trials to thin the temperature boundary layer.

The above mentioned methods to improve heat transfer efficiency usually result in enlargement of facility size and fluid pressure drop in the heat exchanger. For example, the pressure drop increase linearly to the square of fluid velocity ${ }^{17-19)}$ in contrast that the heat transfer coefficient is linear to the power less than unity of the fluid velocity. ${ }^{3)}$ Therefore the improvement of efficiency of heat exchanger includes difficult trade-off relations, and some proposals for such problem have been proposed. ${ }^{20-23)}$ This study comes up with an idea to remove physically the temperature boundary

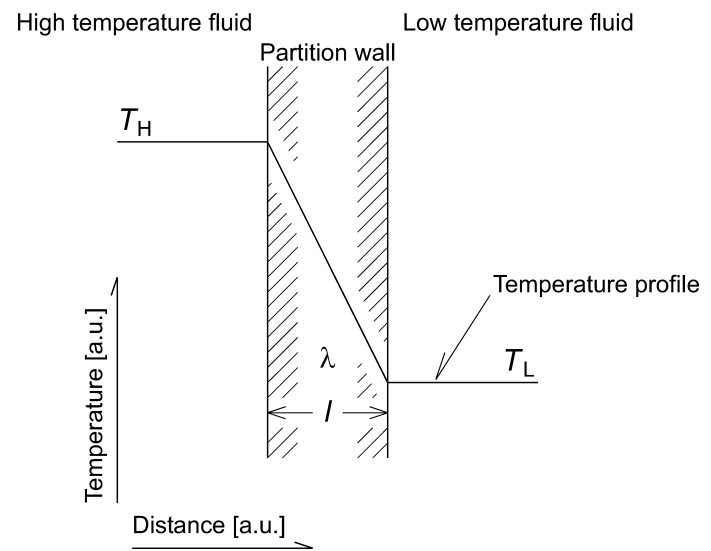

Fig. 2. Ideal temperature profile without temperature boundary layer.

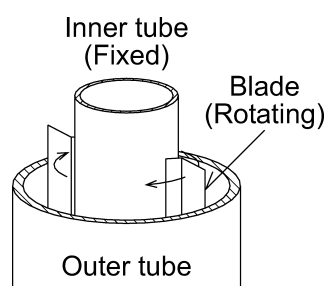

Fig. 3. Schematic diagram of scraped-surface heat exchanger.

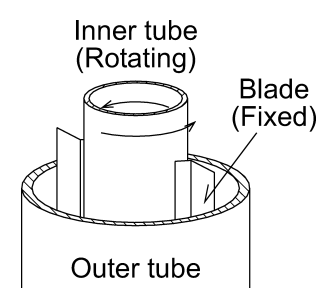

Fig. 4. New concept of scraping temperature boundary layer.

layer. In other words, the boundary layer is scraped by solid blade and feed fresh fluids to the surface of the partition wall. Therefore the ideal temperature profile around the partition wall becomes one shown in Fig. 2. For this ideal temperature profile, the heat transfer resistances of inner and outer temperature boundary layers disappear and the overall heat transfer coefficient can be expressed as

$$
\frac{1}{h_{\mathrm{ov}}}=\frac{1}{\lambda / l}
$$

Therefore the drastic improvement of the heat exchange efficiency is expected with this concept. Based on this concept, scraped-surface heat exchanger in which the moving blades scrape the boundary layer is already proposed (Fig. 3). ${ }^{24,25)}$ Contrarily to this, the heat exchanger proposed in this paper has fixed blades and moving partition wall as shown in Fig. 4. Comparing these two concepts in doublepipe type heat exchanger; the scraped-surface heat exchanger moves large blades traversing in fluid flow and needs fairly complex mechanics. The new concept heat exchanger rotates only the inner tube, thus its appearance seems static and the structure is simple although it needs mechanics to rotate the inner tube. In the following section, a prototype of the heat exchanger having this concept is constructed and its performance is measured. In this paper 
the heat exchangers which have blades on both sides of the inner tube are called DFR (Double Film Robber (scraping)) heat exchangers and ones have the blades on only either inside or outside are called SFR ( exchangers.

\section{Experiments}

The prototypes of the SFR and DFR are made. The structure of the DFR heat exchanger is schematically shown in Fig. 5. Fundamental structure of SFR and DFR is same as the double-tube type heat exchanger. One of two heat exchanging fluids flow inside the inner tube and the other fluid flows the annular space between inner and outer tubes. These fluids exchange heat through inner tube as they flow countercurrently. Typical size of the heat exchanger is as follows. Inner diameter and the thickness of inner tube are 47 and $1.9 \mathrm{~mm}$, respectively, and the inner tube is made of copper. Inner diameter of the outer tube (shell) is $105 \mathrm{~mm}$. Effective length for heat exchange of the inner tube is $262 \mathrm{~mm}$. The outside of the inner tube is connected to the end flanges with bearing and is able to rotate freely. The both ends of the inner tube are closed by plugs which is settled with bearing. These plugs are stable even the inner tube is rotating. The fluid passing inside the inner tube is fed and discharged through hole socket put onto these plugs. The outside fluid is fed and discharged from the inlet and outlet ports settled on the side near the ends of the outer tube. The inner tube is driven by the motor and its rotation speed is controlled. For outside of inner tube two blades are inserted. The tip of the blade is made of Teflon for smooth movement of the inner tube, and touches to the surface of inner tube. The blade is supported from the outer tube and the spaces surrounded by the blade, the supports and the outer tube are holes to pass the outer fluid. Regarding inside of the inner tube, four blades are inserted. These blades are supported from a support column which is inserted on the center axis of the heat exchanger. For the SFR only inside blades are used. As mentioned in the previous section, all blades are fixed and stable.

Figure 6 shows the schematic diagram of the experimental apparatus for water-water system. The water is heated up and its temperature is maintained in a hot bath. The hot water is sent to the heat exchanger by the pump at the constant flow rate. Similarly the cold water is fed from the cold bath. Thermocouples are inserted into the water piping, hot and cold baths and so on, and the temperatures at the various positions in the apparatus are recorded by the data acquisition system. For water-steam combination, the hot bath is replaced by the steam generator and the steam is fed to the heat exchanger. For the combination including air as the fluid, air is sent from the compressor through temperature controller unit.

The experiments are carried out as following procedures. A fluid is fed to the inner tube at constant flow rate and temperature. The other fluid is fed to the outside of inner tube at constant flow rate and temperature. The rotation of the inner tube is set at certain revolution. Inflow and outflow temperatures of both fluids are measured continuously until the all temperatures becomes stable (steady state). The heat transfer rate from the outer fluid to the inner fluid is

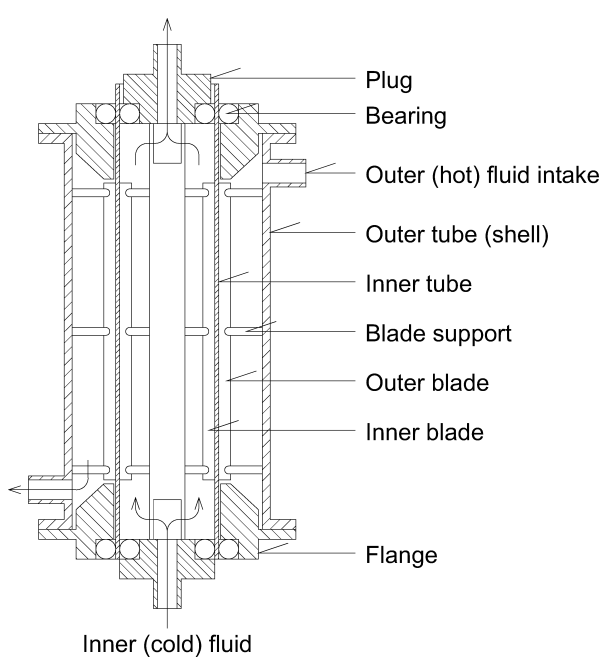

Fig. 5. Details of DFR heat exchanger.

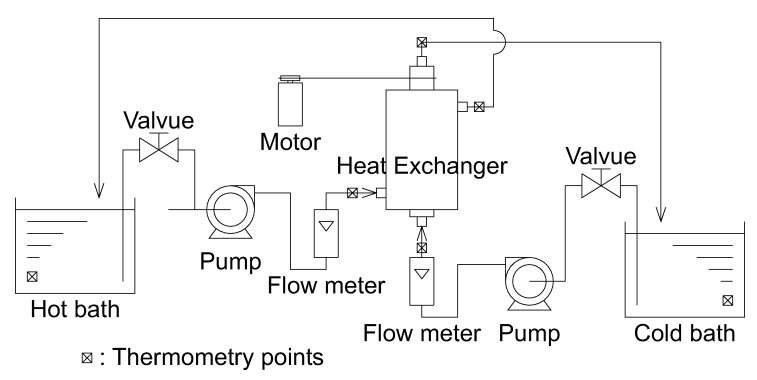

Fig. 6. Schematic diagram of experimental apparatus.

calculated based on the temperature difference between inflow and outflow temperatures, flow rate and specific heat capacity of the inner fluid as

$$
Q=F C_{P}\left(T_{\text {out }}-T_{\text {in }}\right)
$$

if the specific heat capacity varies widely within the measured temperature range, it can be calculated by

$$
Q=F \int_{T_{\mathrm{in}}}^{T_{\text {out }}} C_{P} d T
$$

In this study the heat transfer rate is calculated based on the temperature change of water of which specific heat capacity is $4.184 \mathrm{~kJ} \mathrm{~kg}^{-1} \mathrm{~K}^{-1}$. The heat transfer rate is substituted into Eq. (1), then the overall heat transfer coefficient can be obtained.

In this study the high temperature fluid is fed to the outer part of the heat exchanger although various combinations of two fluids are examined, for example water-water, steam-water, water-air, and so on. The examined conditions are summarized in Table 1.

\section{Results and Discussions}

\subsection{Experimental Results}

Figure 7 shows the effect of inner tube rotation on the overall heat transfer coefficients for water-water system in the DFR heat exchanger. The overall heat transfer coefficients without inner tube rotation are in the range from 1200 to $1600 \mathrm{~W} \mathrm{~m}^{-2} \mathrm{~K}^{-1}$ depending on the operating con- 
Table 1. Summary of experimental conditions.

\begin{tabular}{|c|c|c|c|c|c|c|}
\hline \multirow[b]{2}{*}{ Run \# } & \multicolumn{3}{|c|}{ Low temperature fluid } & \multicolumn{3}{|c|}{ High temperature fluid } \\
\hline & Fluid & $\begin{array}{c}\text { Flow rate } \\
{[\mathrm{kg} / \mathrm{s}]}\end{array}$ & $\begin{array}{c}T_{\text {in }} \\
{\left[{ }^{\circ} \mathrm{C}\right]}\end{array}$ & Fluid & $\begin{array}{c}\text { Flow rate } \\
{[\mathrm{kg} / \mathrm{s}]}\end{array}$ & $\begin{array}{c}T_{\text {in }} \\
{\left[{ }^{\circ} \mathrm{C}\right]}\end{array}$ \\
\hline 42 & water & 0.167 & 14.2 & water & 0.167 & 48.2 \\
\hline 43 & water & 0.100 & 14.2 & water & 0.167 & 51.6 \\
\hline 44 & water & 0.0833 & 13.6 & water & 0.167 & 42.5 \\
\hline 53 & water & 0.0833 & 29.3 & water & 0.167 & 66.7 \\
\hline $6^{*}$ & water & 0.167 & 43.1 & steam & \begin{tabular}{ll|}
-- \\
-
\end{tabular} & 103.1 \\
\hline $12^{*}$ & water & 0.167 & 42.0 & steam & --- & 103.1 \\
\hline 78 & Air & $1.00 \times 10^{-4}$ & 21.9 & water & 0.117 & 85.3 \\
\hline 89 & Air & $1.00 \times 10^{-3}$ & 16.1 & steam & --- & 100.2 \\
\hline $100^{* *}$ & water & 0.0833 & 18.8 & Air & $3.01 \times 10^{-3}$ & 102.4 \\
\hline $101^{* *}$ & water & 0.0833 & 12.8 & Air & $3.01 \times 10^{-3}$ & 108.5 \\
\hline
\end{tabular}

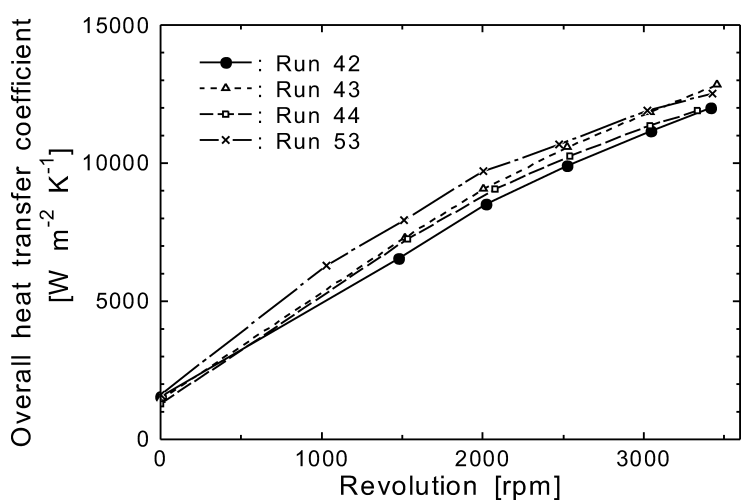

Fig. 7. Overall heat transfer coefficients for water-water systems in DFR heat exchanger.

dition. The heat transfer coefficients increases with increase in the revolution of the inner tube rotation, and the coefficients reach around $10000 \mathrm{~W} \mathrm{~m}^{-2} \mathrm{~K}^{-1}$ when the revolution is $3500 \mathrm{rpm}$. In other words, the overall heat transfer coefficient increases about seven times compared to the one without tube rotation. This trend is common regardless of flow rate and temperature of fluids. This result shows that the concept of the stripping the temperature boundary layer and the implementation by the inner tube rotation work properly and effectively.

The effect of inner tube rotation on overall heat transfer coefficient for water-steam system in the SFR heat exchanger is sown in Fig. 8. In this system water and steam are inner and outer fluids, respectively. In condensation heat transfer of steam without non-condensable gas, the temperature boundary layer is negligible because the most transferred heat is supplied by the latent heat of condensation. Therefore the steam-water system employs the SFR configuration with only inner (water side) blades. Figure 8 shows two runs with different condensation sates, namely partially and fully dropwise condensation (Runs 06 and 12, respectively). The overall heat transfer coefficients without inner tube rotation are in the range from 3800 to $5000 \mathrm{~W} \mathrm{~m}^{-2} \mathrm{~K}^{-1}$. Similarly to the water-water system the heat transfer coefficient increases with the increase in the revolution of inner tube rotation. The heat transfer coefficients in fully dropwise condensation are higher than ones in partially dropwise condensation. The increment of the heat transfer coefficient is larger than that in the water-

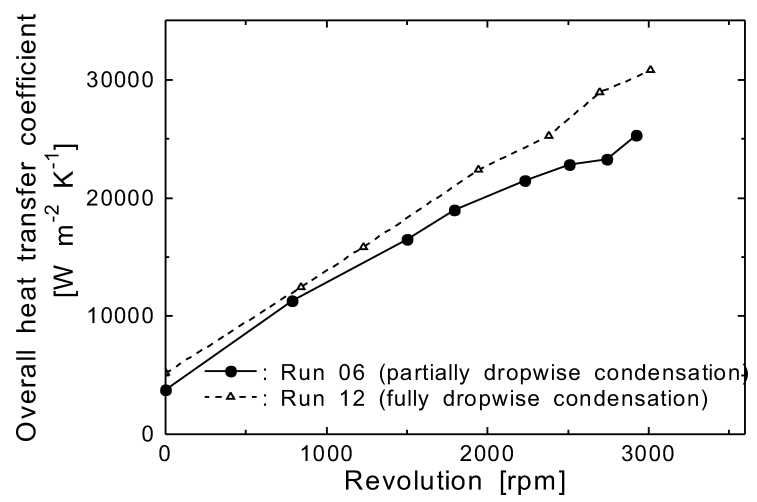

Fig. 8. Overall heat transfer coefficient for water-steam systems in SFR heat exchanger.

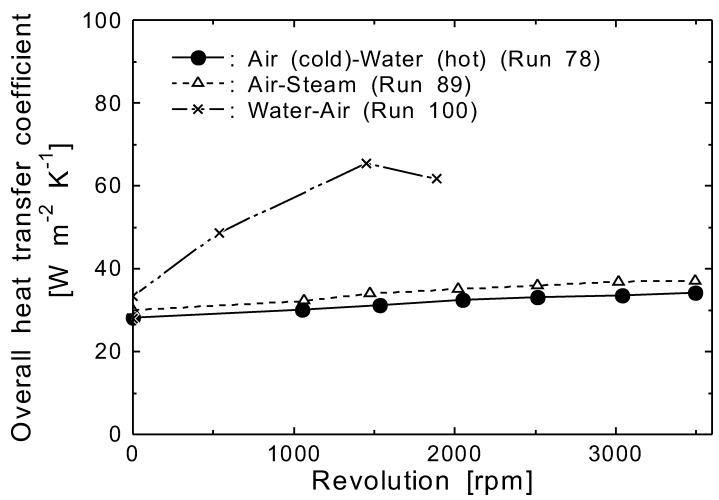

Fig. 9. Overall heat transfer coefficients for air-water, air-steam and water-air systems in DFR heat exchanger.

water system, and reaches up to about $30000 \mathrm{~W} \mathrm{~m}^{-2} \mathrm{~K}^{-1}$. It is considered that the heat transfer rate in steam-water system is controlled by the heat transfer resistance of the temperature boundary layer of water. Thus the scraping the inner boundary layer contributes to improvement of the heat transfer efficiency. Furthermore, the steam flow has higher capacity for heat supply compared to the hot water, then the increment of the heat transfer coefficient is larger.

Figure 9 shows the variation of the overall heat transfer coefficient for air-water, air-steam and water-air systems in the DFR heat exchanger. The overall heat transfer coefficients for these systems without inner tube rotation is about $30 \mathrm{~W} \mathrm{~m}^{-2} \mathrm{~K}^{-1}$ and are much smaller than that of previous systems. Although the overall heat transfer coefficients increases with the increase in the revolution of the inner tube rotation, the heat transfer coefficient reaches about $35 \mathrm{~W} \mathrm{~m}^{-2} \mathrm{~K}^{-1}$ when the revolution is $3500 \mathrm{rpm}$, in other words the impact of the inner tube rotation is limited for gas systems. The variation of the heat transfer coefficients of the system including gas can be explained as follows. a) The Prandtl number $\left(C_{\mathrm{p}} \mu / \lambda\right)$ of gas is usually lower than that of liquid, and the heat transfer coefficient is also smaller, thus the values of heat transfer coefficient are smaller. b) Viscosity of gas is usually lower than that of liquids, and the mixing of the gas due to the scraping blades becomes smaller. This results in that the supply of fresh air to the heat transfer surface becomes small. c) The volumetric heat capacity of air is small so that the heat supplying rate to the heat transfer surface could become insufficient. Furthermore d) the dimensions of the heat exchanger used 
in these experiments are not optimized for gas systems.

\subsection{Modification for Heat Exchanger for Gaseous Sys- tem}

As shown in the previous section, the heat exchanging systems including gas showed the lower overall heat transfer coefficient and its increment with the inner tube rotation was unremarkable. It is considered that the weak mixing of air flow by the inner tube rotation due to low viscosity of gas is one of the reasons for this trend. A countermeasure to increase the mixing is to increase entrainment of gas by the inner tube movement. For this issue, numerous grooves are engraved on the surface of the inner tube as shown in Fig. 10. Thirty three rectangular grooves of $0.8 \mathrm{~mm}$ in depth and $2.5 \mathrm{~mm}$ in width are longitudinally engraved in parallel. The variation of the overall heat transfer coefficient for hot air-cold water system in which the water is fed to the inner tube and heated by the hot air supplied to the outer part is shown in Fig. 11. The heat transfer coefficient of the grooved tube without rotation is about $37 \mathrm{~W} \mathrm{~m}^{-2} \mathrm{~K}^{-1}$ and slightly higher than that of smooth tube $\left(33 \mathrm{~W} \mathrm{~m}^{-2}\right.$ $\mathrm{K}^{-1}$ ). It is considered that this increase in the heat transfer coefficient is brought by the increase in the heat transfer area due to grooving because the heat transfer coefficient of grooved tube becomes almost same value as smooth tube when the increase in the heat transfer area due to the grooving. The increment of the heat transfer coefficient with inner tube rotation, however, is larger in the grooved heat exchanger. The increment of the heat transfer coefficient for the grooved tube at $1800 \mathrm{rpm}$ of rotation is about twice as smooth tube and the coefficient reaches about $100 \mathrm{~W}$ $\mathrm{m}^{-2} \mathrm{~K}^{-1}$. From these results it is considered that the entrainment of the air by the inner tube rotation and the fluid mixing is enhanced by the bumpy surface of grooved tube. Although the value of the heat transfer coefficient for gaseous system is still smaller compared with the liquid system and it needs further optimizations, it is confirmed

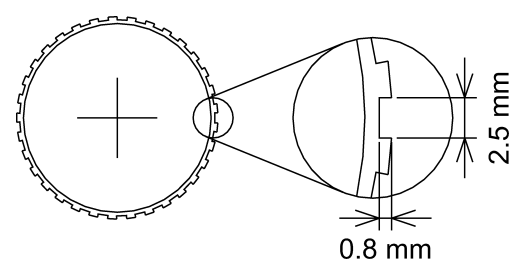

Fig. 10. Cross section of grooved inner tube.

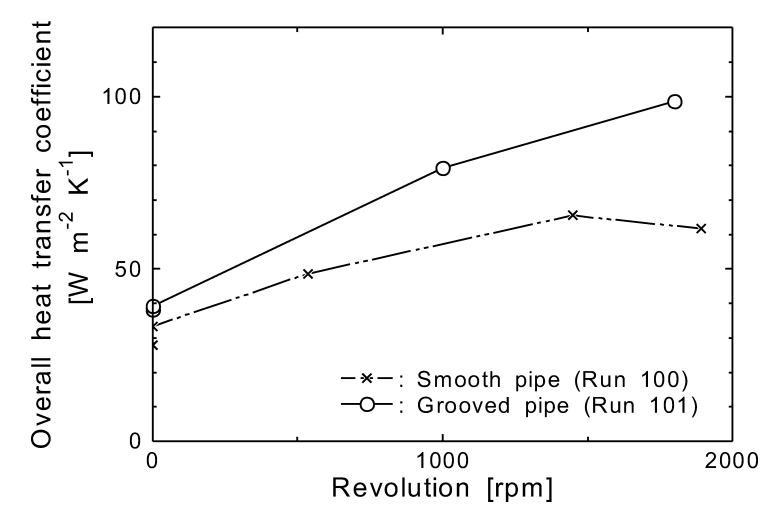

Fig. 11. Overall heat transfer coefficients for water-air system in DFR heat exchanger with grooved inner tube. that the grooving is an effective method to improve the heat transfer efficiency in the heat transfer system including gas.

\section{Conclusions}

This paper proposed a new concept to improve heat transfer efficiency of heat exchangers. In this concept the temperature boundary layers are scraped by rigid blades from moving heat transfer surface. This idea was implemented in double tube type heat exchangers and was examined their performance. The results showed that the overall heat transfer coefficients increased by scraping effect especially in the liquid-liquid or liquid-steam systems, and the effectiveness of the concept was confirmed.

\section{Nomenclature}

$A$ : Heat transfer area $\left(\mathrm{m}^{2}\right)$

$C_{P}: \quad$ Specific heat capacity $\left(\mathrm{J} \mathrm{kg}^{-1} \mathrm{~K}^{-1}\right)$

$d:$ Diameter $(\mathrm{m})$

$F$ : Mass flow rate $\left(\mathrm{kg} \mathrm{s}^{-1}\right)$

$h$ : Heat transfer coefficient $\left(\mathrm{W} \mathrm{m}^{-2} \mathrm{~K}^{-1}\right)$

$Q: \quad$ Heat transfer rate $(\mathrm{W})$

$T: \quad$ Temperature $(\mathrm{K})$

$u$ : Fluid velocity $\left(\mathrm{m} \mathrm{s}^{-1}\right)$

Greek

$\lambda$ : Thermal conductivity $\left(\mathrm{W} \mathrm{m}^{-1} \mathrm{~K}^{-1}\right)$

$\mu$ : Viscosity $(\mathrm{Pa} \cdot \mathrm{m})$

$\rho$ : Density $\left(\mathrm{kg} \mathrm{m}^{-3}\right)$

Subscript

$\mathrm{H}$ : High temperature

in: Inflow

L: Low temperature

out: Outflow

ov: Overall

\section{REFERENCES}

1) N. Maruoka, T. Mizuochi, H. Purwanto and T. Akiyama: ISIJ Int., 44 (2004), 257.

2) T. Ariyama, T. Akiyama and T. Nagasaka: J. Jpn. Inst. Energy, 85 (2006), 862 .

3) H. Purwanto and T. Akiyama: Int. J. Hydrogen Energy, 31 (2006), 491.

4) H. Purwanto, N. Maruoka and T. Akiyama: J. Chem. Eng. Jpn., 39 (2006), 531.

5) L. Zhang and T. Akiyama: Int. J. Exergy, 6 (2009), 214.

6) N. Okinaka and T. Akiyama: Jpn. J. Appl. Phys., 45 (2006), 7009.

7) L. Zhang, T. Tosho, N. Okinaka and T. Akiyama: Proc. 6th Japan-Brazil Symp. Dust Proc.-Energy-Env. Metallur. Industries, ABM, Sao Paulo, (2006), 44.

8) T. Tosho, T. Watanabe, N. Okinaka and T. Akiyama: Ferrum, 12 (2007), 51

9) N. Okinaka, L. Zhang and T. Akiyama: Proc. 7th Japan-Brazil Symp. Dust Proc.-Energy-Env. Metallur. Industries, ABM, Sao Paulo, (2008), 285.

10) T. Akiyama: J. Jpn. Inst. Energy, 86 (2007), 161.

11) N. Maruoka and T. Akiyama: Energy, 31 (2006), 1632.

12) A. Kaizawa, H. Kamano, A. Kawai, T. Jozuka, T. Senda, N. Maruoka, N. Okinaka and T. Akiyama: ISIJ Int., 48 (2008), 540.

13) A. Kaizawa, H. Kamano, A. Kawai, T. Jozuka, T. Senda, N. Maruoka and T. Akiyama: Energy Convers. Manag., 49 (2008), 698.

14) A. Kaizawa, N. Maruoka, A. Kawai, H. Kamano, T. Jozuka, T. Senda and T. Akiyama: Heat Mass Trans., 44 (2008), 763.

15) J. P. Holman: Heat transfer 8th Ed., McGraw-Hill, New York, (1997), 285.

16) R. B. Bird, W. E. Stewart and E. N. Lightfoot: Transport Phenomena 
ISIJ International, Vol. 50 (2010), No. 9

2nd Ed., John Wiley \& Sons, New York, (2002), 433.

17) M. C. Potter and D. C. Wiggert: Mechanics of Fluids, Prentice-Hall International, London, (1991), 505

18) R. W. Fox and A. T. McDonald: Introduction to Fluid Mechanics 4th Ed., John Wiley \& Sons, New York, (1992), 347.

19) R. B. Bird, W. E. Stewart and E. N. Lightfoot: Transport Phenomena 2nd Ed., John Wiley \& Sons, New York, (2002), 179.

20) T. L. Ngo, Y. Kato, K. Nikitin and N. Tsuzuki: Exp. Therm. Fluid Sci., 30 (2006), 811.

21) K. Nikitin, Y. Kato and L. T. Ngo: Int. J. Refrig., 29 (2006), 807.
22) T. L. Ngo, Y. Kato, K. Nikitin and T. Ishizuka: Exp. Therm. Fluid Sci., 32 (2007), 560.

23) N. Tsuzuki, Y. Kato, K. Nikitin and T. Ishizuka: J. Nucl. Sci. Technol., 46 (2009), 403.

24) D. Green: Perry's Chemical Engineers' Handbook 6th ed., McGrawHill, New York, (1984), 11.

25) J. L. Boyen: Practical Heat Recovery, Japanese Ed., Japan Technology \& Economic Center, Tokyo, (1977), 229.

26) H. Miyashita, Y. Tsukada, H. Entaiji and A. Takayanagi: Bull. Fac. Eng., Toyama Univ., 30 (1979), 43. 